\title{
Statistical and Probabilistic Extensions to Ground Operations' Discrete Event Simulation Modeling
}

\author{
Linda Trocine ${ }^{1 *}$, Nicholas H. Cummings ${ }^{2 * *}$, Ashley M. Bazzana ${ }^{3 *}$, Nathan Rychlik ${ }^{4 *}$, Kenneth L. \\ LeCroy $^{5 *}$, Grant R. Cates ${ }^{6 * *}$ and Mansooreh Mollaghasemi ${ }^{7 *}$ \\ * DES Modeling \& Analysis Center \\ Productivity Apex, Inc., \\ 3505 Lake Lynda Drive, Suite 206 \\ Orlando, Florida, 32817 USA \\ **KSC Constellation Project Office \\ Kennedy Space Center, Florida, 32899 \\ USA \\ *** DES Modeling \& Analysis Center \\ Science Applications International Corp, \\ 1710 SAIC Drive \\ McLean, VA, 22102 USA
}

NASA's human exploration initiatives will invest in technologies, public/private partnerships, and infrastructure, paving the way for the expansion of human civilization into the solar system and beyond. As it is has been for the past half century, the Kennedy Space Center will be the embarkation point for humankind's journey into the cosmos. Functioning as a next generation space launch complex, Kennedy's launch pads, integration facilities, processing areas, launch and recovery ranges will bustle with the activities of the world's space transportation providers. In developing this complex, KSC teams work through the potential operational scenarios: conducting trade studies, planning and budgeting for expensive and limited resources, and simulating alternative operational schemes. Numerous tools, among them discrete event simulation (DES), were matured during the Constellation Program to conduct such analyses with the purpose of optimizing the launch complex for maximum efficiency, safety, and flexibility while minimizing life cycle costs. Discrete event simulation is a computer-based modeling technique for complex and dynamic systems where the state of the system changes at discrete points in time and whose inputs may include random variables. DES is used to assess timelines and throughput, and to support operability studies and contingency analyses. It is applicable to any space launch campaign and informs decision-makers of the effects of varying numbers of expensive resources and the impact of off nominal scenarios on measures of performance. In order to develop representative DES models, methods were adopted, exploited, or created to extend traditional uses of DES. The Delphi method was adopted and utilized for task duration estimation. DES software was exploited for probabilistic event variation. A roll-up process was used, which was developed to reuse models and model elements in other lessdetailed models. The DES team continues to innovate and expand DES capabilities to address KSC's planning needs.

\begin{tabular}{|c|c|c|}
\hline & & Nomenclature \\
\hline$a$ & $=$ alpha, Type I error, Producer's risk & \\
\hline$\beta$ & $=$ beta, Type II error, Consumer's risk & \\
\hline$H_{0}$ & $=$ null hypothesis & \\
\hline
\end{tabular}

${ }^{1}$ Ph.D., Senior Scientist, Mail Stop: SAIC-LX, email: Linda.Trocine-1@nasa.gov

${ }^{2}$ Technical Manager for Operations Integration, Mail Stop: LX, email: Nicholas.H.Cummings@nasa.gov

${ }^{3}$ Industrial Engineer, Mail Stop: SAIC-LX, email: Ashley.M.Bazzana@nasa.gov

${ }^{4}$ Manager of Space Systems, Mail Stop: SAIC-LX, email: NRychlik@productivityapex.com

${ }^{5}$ Senior DES Analyst, Mail Stop: SAIC-LX, email: Kenneth.L.LeCroy@nasa.gov

${ }^{6}$ Ph.D., Senior Operations Research Analyst, Mail Stop: SAIC-LX, email: Grant.R.Cates@saic.com, Senior AIAA Member

${ }^{7}$ Ph.D., Founder and Chief Executive Officer, email: mmollagha@productivityapex.com.

1

American Institute of Aeronautics and Astronautics 
$\begin{array}{ll}\mathbf{N}(x, s) & =\text { normal distribution, mean } x \text { and standard deviation } s \\ p_{0} & =\text { desired proportion that passes } \\ p_{I} & =\text { proportion of sample that passes }\end{array}$

\section{Introduction}

A $t$ NASA's Kennedy Space Center, ongoing planning has been underway for the ground processing and integration of human-rated launch vehicles and spacecraft, most recently for the Orion Spacecraft, the Altair Spacecraft and the Ares launch vehicles and moving forward for private/public exploration initiatives. The planning involves identification, development; modification, and risk assessment of facilities, ground processing activities, ground support equipment, and budgeting thereof. Additionally, the planning work informs flight hardware design teams on how to improve operability and maintainability of the flight hardware. Among the many tools KSC uses is discrete event simulation (DES), the subject of this paper.

Discrete event simulation is a computer-based modeling technique for complex and dynamic systems whose state changes at discrete points in time and whose inputs may be random variables. In a DES model, activity networks are implemented, task durations are fitted with theoretical or empirical distributions, and constrained resources are allocated across applicable tasks. Models are executed on computers and the random variable outputs are analyzed and interpreted.

This paper provides a brief overview of DES, how it has been used at KSC, and the benefits it is providing to $\mathrm{KSC}$ in its role as a hub for human exploration. We then delve into the description of methods developed and exploited to support the DES analyses for GOP, which may be applied elsewhere, both in aerospace and generally in DES. Among these are an implementation of the Delphi method, an approach to probabilistic event variation, and an overview of how the team rolls up detailed results to be used in less-detailed models to support decision making.

\section{Discrete Event Simulation at Kennedy Space Center}

In this section we provide an overview of DES generally. Then we describe how DES has been used at the Kennedy Space Center along with a description of the benefits to the Center.

\section{A. Overview of DES}

Discrete event simulation (DES) is a method of modeling system behavior under the assumption that the state of the system-described by a collection of variables-changes at discrete points in time, ${ }^{1}$ The computational techniques can be implemented within a computer program via an event scheduling approach that is very efficient, which allows one to model complex systems. There are several commercially available software products that embody DES techniques. We use Arena ${ }^{\circledR}$ software from Rockwell Automation $®$ to provide the DES environment for developing models and providing analysis at NASA's Kennedy Space Center. A significant benefit of simulation, modeling and analysis is that it allows one to conduct experiments and make predictions about system behavior prior to building or modifying a complex system such as a space launch vehicle.

A project such as building a house or preparing a rocket for launch can be modeled with DES and these models can be used to provide valuable information on the project. For example, the likely time to complete the house or get the rocket ready for launch can be estimated with the model. While a simple project schedule could be used by itself to estimate the planned time to build the house or complete the rocket, the simulation model allows one to include uncertainty factors such as resource availability and variability in how long each individual step in the project will take. Running the model once, called a replication, simulates the building of the house or preparing the rocket from start to finish. Many replications of the model are run to determine a probability density function for the time to complete the project e.g., build the house or prepare the rocket. Since each replication will experience different inputs, through the use of different random numbers for process delays, there will be variability in the project duration for each replication. The benefit of this is that we can simulate preparing a rocket for launch with different assumptions so that we can determine the quickest or optimum way in which to prepare the rocket.

Keys to modeling complex systems and providing useful information to decisions makers include: developing good problem statements; working closely with the decision makers; verifying that your model is behaving the way it is intended; performing statistically valid input and output analysis; and validating that the model represents the system under study with sufficient accuracy to make decisions. ${ }^{2}$

2

American Institute of Aeronautics and Astronautics 


\section{B. DES at Kennedy Space Center}

Discrete-event simulation models and the resulting analyses have been utilized by decision makers at KSC for a . number of years. DES expertise and experience at $\mathrm{KSC}$ has been matured greatly, this section provides a brief history of those efforts.

In the 1993-1994 timeframe, a space shuttle Launch Processing Model was developed. ${ }^{3}$ This model was used to predict annual flight rates and could also determine how many 8-hour shifts would be required to perform orbiter processing prior to readiness of orbiter mate to the external tank.

In 1999, KSC entered into a Space Act agreement with the University of Central Florida to build a macro-level model of the space shuttle including manufacturing, refurbishment, ground processing, launch, ascent, on-orbit operations, return to earth, and recovery. ${ }^{4}$ This project was highly successful in developing a valid model and developing a cadre of experts to provide future DES modeling and analysis expertise to NASA.

In 2003, KSC funded the development of a DES tool called the Generic Environment for Modeling Future Launch Operations, GEM-FLO. GEM-FLO is a generic discrete event simulation tool that facilitates the creation of simulation models for modeling ground processing. GEM-FLO accepts launch vehicle design characteristics and operational inputs from the user, and uses these to configure a simulation model that properly reflects the ground processing flow and requirements of that specific launch vehicle. When the simulation model is executed, it provides a number of measures of performance including operations turnaround time, expected flight rate, and resource utilizations, thus enabling users to fairly assess multiple future vehicle designs using the same generic tool. GEM-FLO was used by the Next Generation Launch Technology (NGLT) Program and the Orbital Space Plane (OSP) Program. ${ }^{5,6}$

DES models built specifically for the space shuttle program have been used at KSC to determine how long it would take to complete a sequence of space shuttle launches and how many space shuttle launches could be achieved over a specified period of time. . $^{7,8,9}$

In 2008, the Constellation Ground Operations Project at KSC setup a Discrete Event Simulation Modeling \& Analysis Center to analyze and evaluate the post-Shuttle ground processing operations at KSC. Since that time, models have been developed and extensive analyses have been performed for the majority of the major processing facilities at KSC. This DES capability has been leveraged to address a number of critical questions for the future of KSC ground operations such as flight rate capabilities, resource requirements, facility layout and design, and launch probability.

\section{Benefits of DES for NASA's Exploration Initiatives}

The Constellation program was established with a goal of substantially reducing the cost of human spaceflight in order to facilitate sustainable exploration operations in conjunction with the development of new exploration systems. Lessons learned from the Space Shuttle Program and International Space Station Program prescribe that program operations costs are unaffordable if lifecycle cost implications of decisions made during development are ignored or poorly understood. Indeed, the gross majority of life cycle costs are incurred in the operational phase of large, long-term programs such as Constellation. Determined to meet the objective of sustainable cost for ground processing and launch operations of the Constellation program, the Ground Operations Project at KSC established a systems engineering approach to operations planning, in essence, "designing the operations of the systems" in conjunction with designing the Constellation systems themselves. This approach provides a key feedback loop that allows systems designers and program management to understand the operational and ultimately lifecycle cost implications of their system design decisions. A critical enabling tool to this approach is DES. In much the same sense that modern CAD software allows designers to model the structures and mechanisms of a hardware system, DES allows the operations team to model all of the processes, interdependencies, and uncertainties of a projected processing flow, and evaluate the response to key operability metrics.

An early application of DES in the Constellation Program was an analysis of the preferred layout of the Vehicle Assembly Building (VAB), where the Ares I and Ares V rockets would be stacked and tested on their Mobile Launchers. The VAB has four large integration bays, each capable of supporting the stacking of a vehicle. However, the bays share cranes, transfer aisle space, and have other key interdependencies that drive complex interactions when multiple vehicles are integrated at once, as would be the case for supporting lunar and eventually Mars exploration missions. A DES was constructed that modeled all of the stacking and integration processes in the $\mathrm{VAB}$, including seizure of key resources and wait time due to operational clears associated with hazardous operations, and several different launch campaign scenarios were evaluated in the simulation. Ultimately, certain layouts proved to be considerably more efficient and a layout was chosen.

Another application of DES was in Constellation's requirements formulation period. KSC supported analysis led by the Langley Research Center to determine the optimum launch spacing and order between the Ares I, which 
would carry the crew for the lunar mission, and the Ares V, which would carry their lunar lander. The DES modeled the launch processing flow of the two vehicles, accounting for system reliability, weather, abort zone implications, the Low Earth Orbit loiter capabilities of the spacecraft and propulsion stages, and other key drivers to. determine the relative advantages of the different possible launch orders and separation. Considering the risk posture and potential outcomes that the simulation predicted, the program elected to specify an aggressive 90 minute launch separation and elected to protect for launching either vehicle first, depending on the specifics of the mission. ${ }^{10,11}$

In support of the Ground Operations Preliminary Design Review, DES has been used extensively to analyze compliance of the Constellation Systems with respect to several key system requirements, including launch rate, launch spacing, and vehicle processing operational timelines. DES was also used to confirm that the numbers of resources required to process Ares I and Orion are within the budget levels allocated.

Perhaps the most important applications of DES were in validating Ground Operations "single-string" processing architecture. The Apollo and Space Shuttle programs both utilized multiple copies of major ground systems infrastructure elements, such as launch pads, mobile launch platforms, Launch Control Center firing rooms, and $\mathrm{VAB}$ high bays. While this approach provided flexibility and capability, it was also very costly to maintain. In order to substantially lower launch site operations costs, the Ground Operations Project boldly proposed a single-string processing architecture, whereby only single units of major infrastructure elements would be developed for Ares I/Orion. DES was used to validate that the critical path processing flows for Ares and Orion were kept in check, and Ground Operations could indeed meet the launch manifest required by the program with acceptable risk.

In part due to state-of-the-art operations planning tools such as DES, as of PDR, it is projected that the Ground Operations cost for the Ares I/Orion will be considerably less than the Space Shuttle or Apollo, meeting the goal set for the Constellation Program. As KSC's role as the nation's embarkation point for humankind's journey into the cosmos evolves, DES will continue to play a critical role in optimizing the operations of the launch complex.

\section{Discrete Event Simulation Extensions}

Planning the ground and launch processing at KSC to optimize facility space, resources, ground support equipment, and personnel, has been the focus of the DES Modeling \& Analysis Center. The center has developed and exploited a variety of methods and tools to support KSC's launch 'technology and development efforts to continue its role as a world-class hub for human spaceflight. In this section we describe three such methods, the Delphi method for input distributions, probabilistic event variation, and a level-of-detail roll up method.

\section{A. Delphi Method}

Immediately after the creation in 2008 of the DES Modeling \& Analysis Center at Kennedy Space Center, DES modeling efforts were undertaken to describe and experiment with the planned ground processing flow of the Orion Spacecraft. An activity network of the flow had been developed, but, because the Orion Spacecraft is new, no relevant historical data were available for the task durations used in the DES model. Therefore a method for generating task duration estimates in the absence of historical data was needed; the team proposed the use of the Delphi Method for this purpose.

\section{Common Cause Variability in Task Durations}

One of the major benefits of DES modeling is that the task durations are modeled not as deterministic values but rather as variable quantities that may take on a range of values. Figure la illustrates the use of a deterministic point estimate of a task-duration. Deterministic point estimates equate to statements such as this: " $100 \%$ of the times this process is done, it will take 4 hours". DES is exploited when task durations are modeled with a distribution, such as Figure 1b. Statements may be made such as "the task will take between 2 and 8 hours", or "the task will take 4 hours most of the time", or " $70 \%$ of the times this task is executed its duration will be between 3 and 5 hours". Such distributions account for the uncertainty due to "common cause" variability, which may be from seasonal factors, day-of-the-week factors, minor rework, minor adjustments, cure time, and so forth. These distributions do not account for "special cause" variability, which may be due to learning curves, unplanned work, and contingencies. Special cause events may be modeled in DES as a branch to a contingency logic flow.

Because task duration distributions are preferable to deterministic point estimates the DES team chose to use the Delphi Method to collect task duration estimates. 


\section{Reasons for using the Delphi Method}

The Delphi method is a structured elicitation method for forecasting, estimating, and planning used with a group of subject matter experts (SMEs) in the absence of sufficient data. The team employs the Delphi method in estimating input quantities used in process models.

The Delphi Method was originally developed and introduced by the Rand Corporation in the 1950 s and first discussed in Dalkey and Helmer technical reports. ${ }^{12}$ The genesis of the method was Project Delphi sponsored by the U.S. Air Force to obtain the most reliable consensus of opinion among a group of experts in enemy targeting decisions. It has been used for highly complex issues beyond
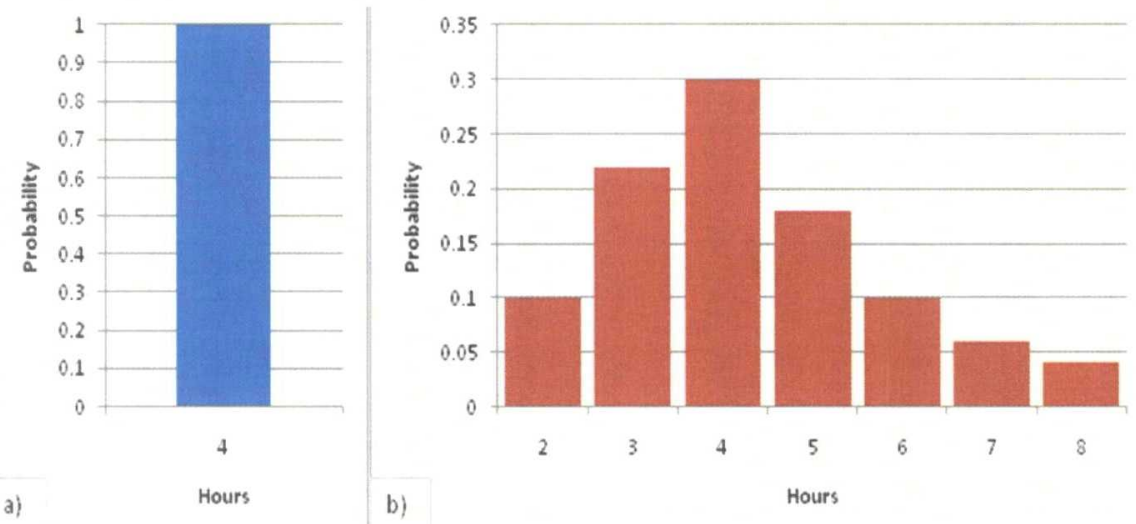

Figure 1. Task Durations: a) Point Estimate b) Distribution Estimate

forecasting such as waste water planning, drug abuse policies, plastics industry forecasting, and the future of the steel industry. An overview of the method follows. First several subject matter experts (SMEs) are each individually given a task of providing an estimate, forecast, or viewpoint on a specific question. Their responses are kept anonymous. The collection of responses are tallied, quantified, or otherwise assembled by a facilitator. The anonymous summaries are sent back to the group of SMEs for revision in a second round, if needed. SMEs respond again, providing their opinion again, with consideration of the anonymous feedback of their peer SMEs from the prior rounds. Within 2 or 3 rounds, consensus is formed.

There are numerous benefits to the Delphi method over other group elicitation methods. First, the SMEs have anonymity unlike group meetings. This avoids dominance of a few individuals in the group setting. All SMEs get equal time. Conformance of opinion is avoided since opinions are provided privately. This approach avoids competition among SMEs and embarrassment among SMEs for unpopular views.

Because of these features, better opinions and forecasts are reached. This is due to the time for thinking and reflecting by SMEs and the flexibility to participate at one's convenience. Broader ideas are often found and there is a lower probability of fixation on one idea. Individuals focus on the problem rather than on how they present themselves in a group meeting. ${ }^{13}$

The Delphi method also provides benefits to the organization. The time impact on SMEs is minimized, scheduling conflicts of a group meeting are avoided, and there are neither travel expenses nor time away for group meetings in other cities. Team interactions are positive, too.

Finally there are benefits of this approach to the DES models. The method has been shown to be a scientifically valid approach of estimating and forecasting in the absence of existing data and provided well demonstrated results in its past use. It is less intrusive, more objective, and a more reliable approach for the subjective estimation of task durations. Convergence to unbiased, independent, knowledge-representative estimates for task durations result from its use. $^{14}$

\section{Input Data Collection and Analysis Approach}

For DES models, the list of tasks needing task duration estimates, along with the work breakdown structure (WBS) code for the task, columns for entering the minimum task duration, the most likely task duration, and the $95^{\text {th }}$ percentile (near-maximum time) task duration, a column for entering the rationale for a task duration estimate, and columns with the names of SMEs with expertise for the task were assembled in a Microsoft ${ }^{\circledR}$ Excel ${ }^{\circledR}$ spreadsheet. This spreadsheet was then distributed to a list of SMEs generated by the team. The SMEs were provided instruction, both written and via a workshop, which included the illustration in Figure 2, on how to complete the spreadsheet along with the context of the tasks that they were estimating, specifically various conceptual models of the process being considered. 
The SMEs completed the spreadsheets, providing minimum, most likely, and $95^{\text {th }}$ percentile task duration estimates on the specific tasks for which they have expertise. Some SMEs had only a few tasks while other SMEs had hundreds of tasks to estimate.

The spreadsheets were returned to a DES analyst. The task time data were analyzed for convergence, and if needed specific tasks were distributed again to SMEs for revision. Once converged, the median response among the set of responses for each of the three elements of the triad was computed. The triads of median results were then used to fit theoretical continuous

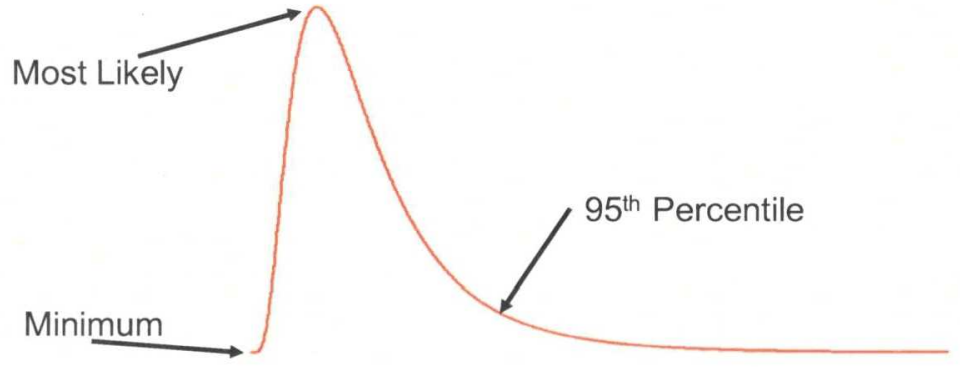

Figure 2. Fitting Task Duration Triads distributions using ExpertFit ${ }^{\circledR}$.

ExpertFit may be used to analyze historical data when they are available and are accurate, or in this case, ExpertFit may be used on Delphi Method outputs. The Delphi results (minimum, most likely, and $95^{\text {th }}$ percentile) were used as inputs in ExpertFit to generate a curve, as illustrated in Figure 2. ExpertFit is distributed by Averill M. Law \& Associates. According to the User's Guide, ${ }^{15}$

"ExpertFit will automatically and accurately determine which probability distribution best represents your data set, and do so in a few seconds. Its distribution-selection algorithm was developed by evaluating 15 heuristics on 35,000 data sets, with the analysis of the data taking six months. ExpertFit has 40 distributions, 30 high-quality graphical plots, 4 technically correct goodness-of-fit tests, sample sizes of 100,000, interactive histograms, extensive support for simulation modeling, a distribution viewer, batch mode, comprehensive context-sensitive help, and a User's Guide with 8 complete examples."

In the absence of historical data, ExpertFit provides only three alternative distributions to fit with a triad: the triangular, Weibull, and lognormal distributions. ExpertFit recommends Weibull and lognormal as the most useful for task duration times.

\section{Results of the Delphi Method}

The Delphi Method was used with the Orion Processing Team first, as a pathfinder. This process took a total of $3 \frac{1}{2}$ months, which spanned method proposal, SME list development, task list preparation, training workshops for SMEs, distribution, reminders and follow up, ending with the analyses. The response rate for the initial project was $63 \%$ among SMEs (see Table 1). Anecdotally, response rates depended upon whether experts were funded or not to work on the project, how familiar they were with the proposed ground processing design and vehicle design, and whether they were working exclusively on Constellation or were shared with Shuttle.

Beyond the initial pathfinder, the Orion vehicle design matured over time and new tasks were identified or tasks

Table 1. Delphi Method Response Rates

\begin{tabular}{l|ccc} 
& Responded & Total & $\begin{array}{c}\text { Percent } \\
\text { Responded }\end{array}$ \\
\hline First project & 42 & 67 & $63 \%$ \\
Second project & 22 & 47 & $47 \%$ \\
Third project & 26 & 69 & $38 \%$
\end{tabular}
were revised, updates to the task duration estimates were collected from the SMEs. More recently the Delphi method was also used for task duration estimation for processing the Lunar Spacecraft including Altair and Lunar Surface Systems. Table 1 shows the response rates for these uses while Figure 3 shows the number of tasks estimated by different numbers of SMEs.

Hundreds of tasks were estimated using the Delphi method. Varying numbers of SMEs provided inputs on the tasks, again based on their level and type of expertise. The team found that having at least 3 SMEs on any particular task was the minimum threshold. Handling dozens of SME spreadsheets was somewhat cumbersome. 
Feedback from SMEs indicated that about 3-5 minutes per task was needed to provide most estimates from experience. At times research into historical data or into other factors was needed by SMEs to provide estimates which took much more time and was handled separately from the use of the Delphi Method. Generally, the SMEs at $\mathrm{KSC}$ learned the method quickly. The Delphi method has been used to develop input distributions for hundreds of tasks in several DES models at KSC.

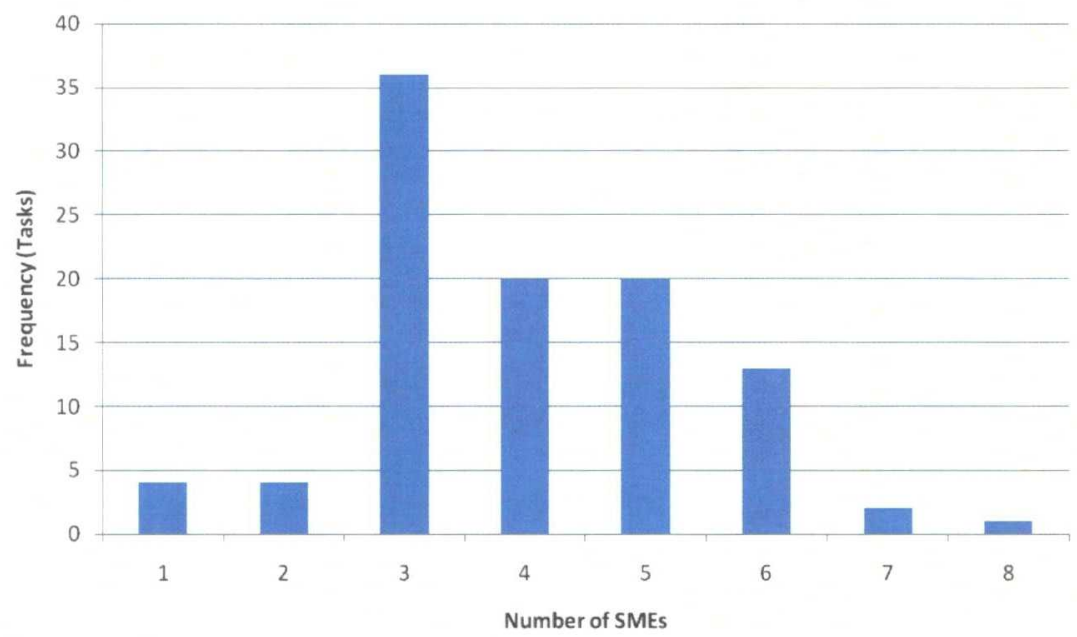

Figure 3. Number of Tasks with Number of SMEs Supplying Estimates

\section{B. Probabilistic Event Variation}

During the identification of methods useful for verifying certain requirements, one requirement called for a contingency crew rescue within 24 hours $95 \%$ of the opportunities. The team responsible for this requirement identified four possible mission phases (launch phase, on-orbit phase, docked phase, prepare-for-landing phase) in which an abort event could occur and six possible zones (mid Pacific, U.S. West Coast, U.S. East Coast, Europe/Africa West Coast, South America West Coast, anywhere else) for which recovery assets had to be positioned or accessible for contingency water landings. The team estimated probabilities of aborts during each mission phase and conditional probabilities that a landing would occur in any of the six zones given that an abort occurred during a particular phase. They developed an analytical tool that used fixed probability estimates of aborts within mission phases to determine the overall probability of meeting the requirement.

The DES Modeling \& Analysis Center proposed extending the team's model by varying the probability estimates that an abort event would occur in any given mission phase. This extension would account for part of the uncertainty in developing these estimates and would allow the requirement to be verified according to the planned Consumer's risk approach, described below. Specifically, in the DES model, rather than modeling the probability that an event occurs as a decimal fraction (e.g. 0.85 for an $85 \%$ chance that an event occurs), the event would occur as in Equation (1) to account for the uncertainty in the 0.85 estimate and to vary the otherwise deterministic model output. Equation (1) is the sum of the deterministic portion, 0.85 , with a normally distributed error term centered at mean 0.0 and standard deviation 0.005 . An example of how this portion of the model could be implemented in Arena is shown in Figure 4. In the top portion of the code, an initialization sequence is executed which samples from the Normal distribution and stores values in the "Phase" and "Zone" variables, as shown in the "Assign" dialog box on the right side of Figure 4. The remainder of the code in Figure 4 shows the flow through the conditional probabilities.

Consumer's risk is the probability of stating that the planned system to meet a requirement will meet it, when in reality the system won't meet it. In the Consumer's risk approach, an experiment on a model is repeated. Each experiment results in a pass or fail outcome, i.e. either the crew were rescued in time (pass) or not (fail). A sample is taken and must fall below the rejection boundary, shown in Figure 5, to conclude that the rescue assets are sufficiently well positioned to meet the crew rescue requirement during contingency landings. The sample is used to make inferences on the performance of the underlying system. Figure 5 illustrates the sampling distributions, which depend only on $\alpha$ (also known as Producer's risk or Type I error), the sample size $n$, and the proportion of items that fail in the sample to the total number of items, $p$. Consumer's risk is also known as $\beta$ or Type II error.

$$
P(\text { phase } 1)=0.85 \pm \mathbb{N}(0.0,0.005)
$$



herein.

Though the team has not implemented this method to date, its novelty and accessibility were worth describing
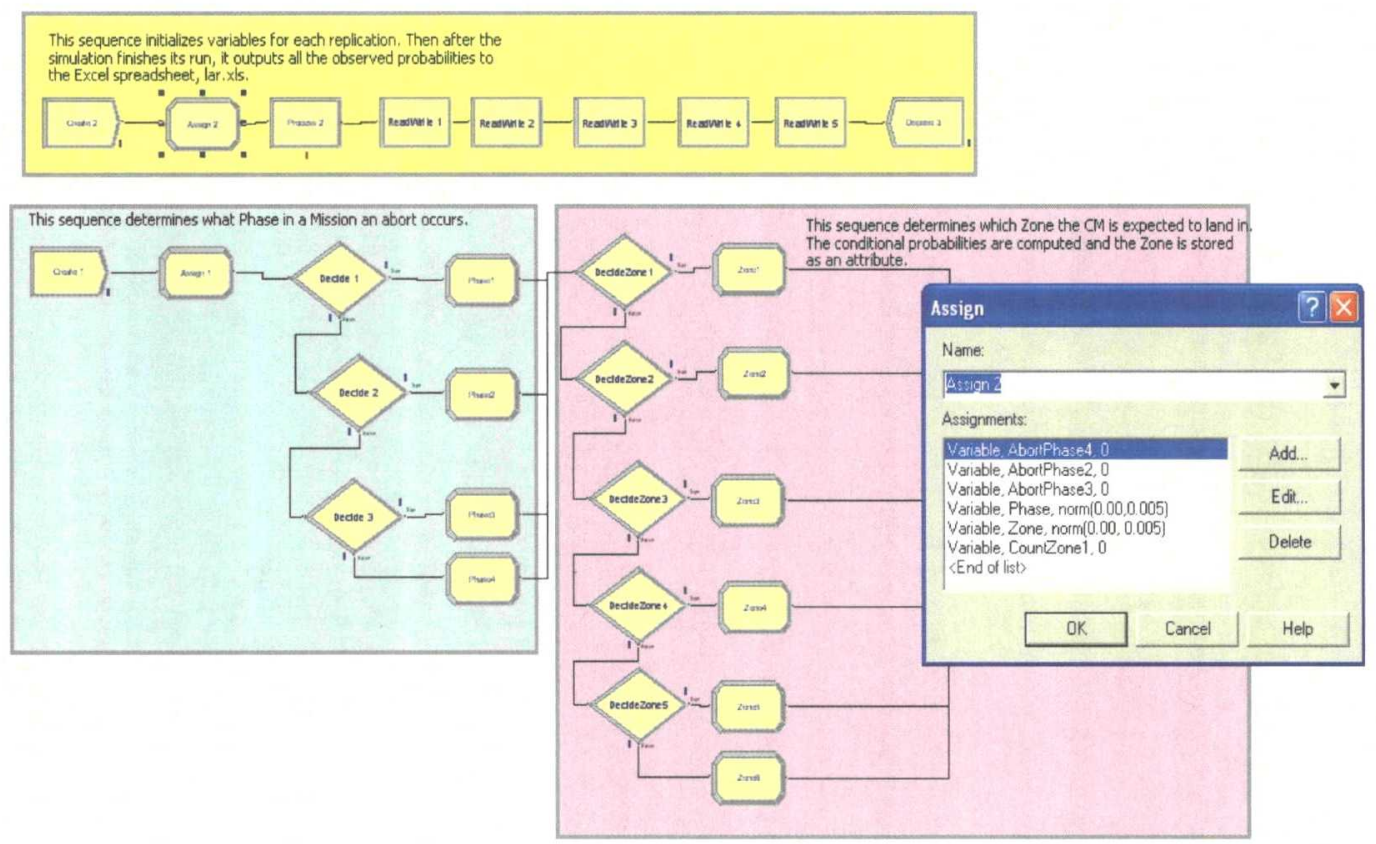

Figure 4. Sample DES Code

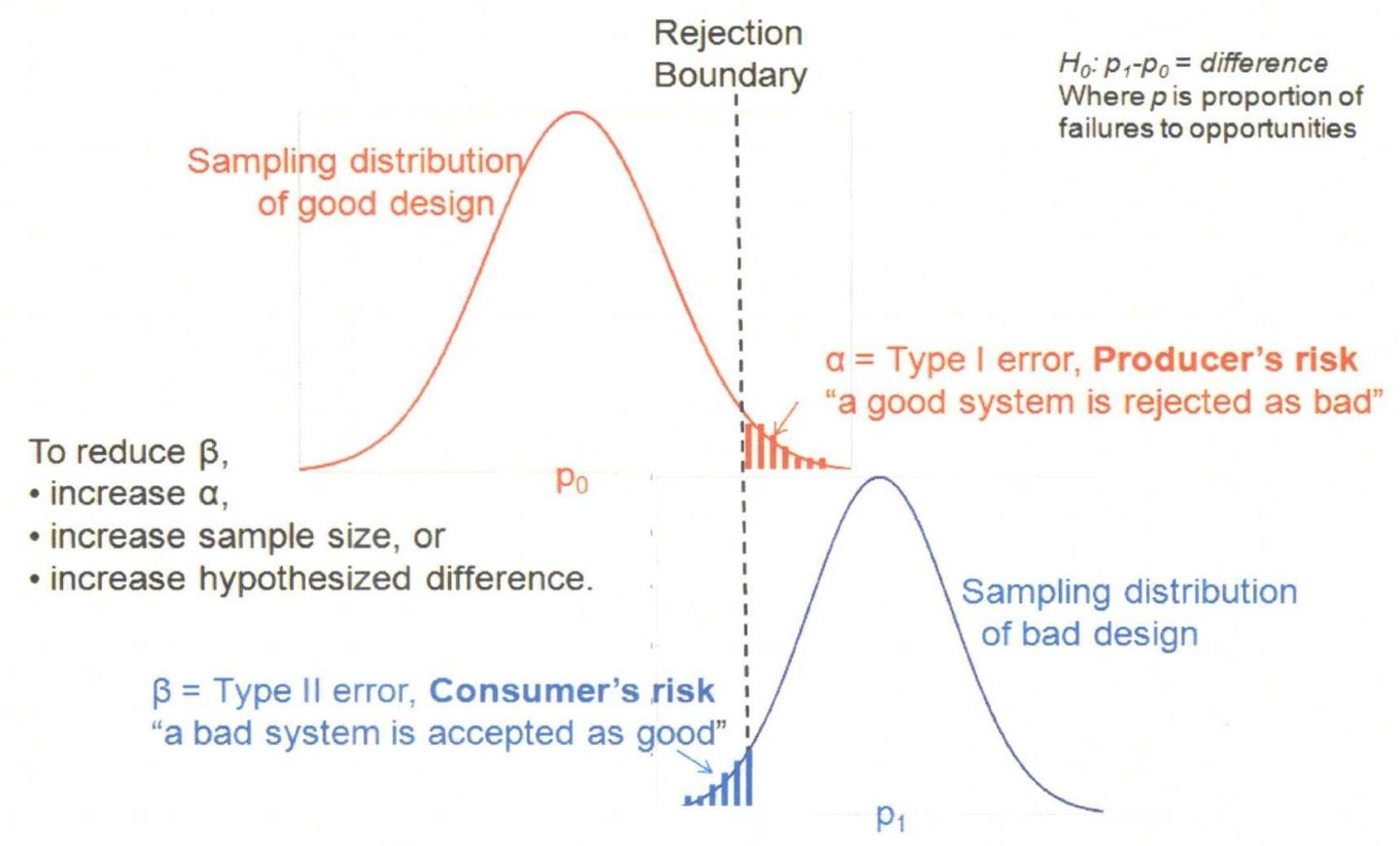

Figure 5. An Illustration of Consumer's Risk

8

American Institute of Aeronautics and Astronautics 


\title{
C. Roll Up Method
}

A large number of DES models have been developed by the team to answer questions across KSC's facilities for processing a variety of spacecraft and flight hardware. At times parts of these models should be reused. One approach is to 'copy' elements of the model, as needed. But that would require maintaining these elements in two different models. Alternatively, elements could be reused by rolling up their values into a summary form. The team found no literature describing methods for rolling up, summarizing, or reusing parts of DES models in a less detailed form. Instead the team conducted experiments with sets of contrived detailed task sequences on how best to roll up and reuse them. Among these experiments was one with a $3 \times 3$ design, with independent variables and their levels as shown in Table 2. The number of tasks to be summarized was set to 4,12 , or 30 elements as a controlling variable.

Table 2. Experiment Design for Roll Up Guidance

Controlled Variable
Number of Tasks
4
12
30

Independent Variable
Number of Replications
30
200
1000

\author{
Independent Variable \\ Distributions \\ Triangular \\ Weibull \\ Lognormal
}

The number of replications to execute the model was set to 30,200 , and 1000 to evaluate the effect of this independent variable. The fitted input distributions were all set to triangular, then to all Weibull, and finally all set to lognormal to evaluate the effect of this independent variable.

All 27 combinations of this experiment design were executed. The output data sets of total processing time were fitted using ExpertFit. Based on the means, variances, and subjective interpretations of histograms of the outputs of the models, the independent variables that provided smooth, representative curves that were easy to fit by ExpertFit suggested using 200 replications with underlying lognormal distributions to summarize sequences of more detailed tasks. The lognormal distribution was considered better than triangular and Weibull input distributions for retaining skew. The lognormal is a useful task time distribution for sequences of tasks. The use of 200 replications was better than 30 or 1000 replications: thirty replications was not a sufficiently large number to capture the shape of the distribution of the outputs and ExpertFit produced poor fits. Using 1000 replications resulted in output distributions that appeared to be more symmetric and the mode of the distribution moved closer to the mean. Though the team is using this approach, much more research in this area should be conducted to discover improvements and ensure their validity and appropriateness.

The team next evaluated the effect of adding constrained resources to the detailed model and the effect of parallel processing in the part of the model to be summarized. No discernible negative effects to this approach were uncovered, based on a few simple experiments using the 12-task models. Again, more research should be conducted to better evaluate this approach. Specifically, the theoretical basis for the number of replications and the basis of the lognormal recommendations should be analytically evaluated. And further experimentation to uncover when parallel processing and constrained resources dominate the effect of the task durations should be researched as well.

The roll up approach was implemented by adding record statements to denote the beginning and ending times of the set of tasks to be summarized. The total time interval duration for 200 replications was output into Microsoft Excel. The data were then fed into ExpertFit. ExpertFit produced its best-fitting theoretical distributions, along with parameters and formulas suitable for use in Arena. These formulas were used in the less-detailed models as the representation of the delay duration for the several tasks summarized therein.

\section{Conclusion}

- Kennedy Space Center established the DES Modeling \& Analysis Center in 2008 to inform decision making, aid in planning, minimize life cycle cost, and optimize facility and resource utilization. The DES center continues to reuse the Center's substantial investment in DES over the years to develop and exploit new methods to best position $\mathrm{KSC}$ as the premier hub for human spaceflight and exploration. 


\section{Appendix}

$\begin{array}{ll}\text { DES } & \text { Discrete Event Simulation } \\ \text { GEM-FLO } & \text { Generic Environment for Modeling Future Launch Operations } \\ \text { GOP } & \text { Ground Operations Project } \\ \text { KSC } & \text { Kennedy Space Center } \\ \text { NGLT } & \text { Next Generation Launch Technology } \\ \text { OSP } & \text { Orbital Space Plane Program } \\ \text { SME } & \text { Subject Matter Expert }\end{array}$

\section{Acknowledgments}

The authors thank the Orion Processing Team for being the pathfinder on the Delphi method, the Orion Landing and Recovery Team for being the pathfinder on the probabilistic event variability technique, and the Level II team for supporting the development of the roll-up method. This work was sponsored by the Constellation Program Ground Operations Project at NASA's Kennedy Space Center.

\section{References}

\footnotetext{
${ }^{1}$ Banks, J, Carson, J.S., Nelson, B.L., and Nicol, D.M., Discrete Event Simulation, $3^{\text {rd }}$ Edition, Prentice Hall International Series in Industrial and Systems Engineering, 2001.

${ }^{2}$ Law, A.M., Simulation Modeling \& Analysis, $4^{\text {th }}$ Edition, McGraw Hill, 2007.

${ }^{3}$ Archer, M. and J. Leotta, "Simulation Study: KSC Shuttle Processing," briefing charts 1994. See NASA Tech Briefs, "Software for Planning in a Hierarchical Processing Environment," Feb 1998, pg. 76, for a brief description of this work.

${ }^{4}$ Cates, G.R., Steele, M.J., Mollaghasemi, M., \& Rabadi, G., "Modeling the Space Shuttle," In Proceedings of the 2002 Winter Simulation Conference, edited by E. Yücesan, C.-H. Chen, J. L. Snowdon, and J. M. Charnes, 754-762. Available via www.informs-cs.org/wsc02papers/097.pdf.

${ }^{5}$ Kaylani, A., Mollaghasemi, M., Cope, D., Fayez, S., Rabadi, G. and Steele, M.J., "A generic environment for modeling future launch operations-GEM-FLO: a success story in generic modeling," Journal of the Operational Research Society (2008) $59,1312-1320$.

${ }^{6}$ Mollaghasemi, M., Steele, M.J., Rabadi, G., and Cates, G.R., "A Generic Environment for Modeling Future Launch Operations (GEM-FLO)," World Automation Congress, June 2002, Orlando, Florida

${ }^{7}$ Cates, G.R., and Mollaghasemi, M., "Supporting The Vision For Space With Discrete Event Simulation," In Proceedings of the 2005 Winter Simulation Conference, edited by M. E. Kuhl, N. M. Steiger, F. B. Armstrong, and J. A. Joines, 1306-1310. Available via http://www.informs-sim.org/wsc05papers/159.pdf

${ }^{8}$ Cates, G.R., and Mollaghasemi, M., "A Discrete Event Simulation Model For Assembling The International Space Station," In Proceedings of the 2005 Winter Simulation Conference, edited by M. E. Kuhl, N. M. Steiger, F. B. Armstrong, and J. A. Joines, 1260-1264. Available via http://www.informs-sim.org/wsc05papers/153.pdf

${ }^{9}$ Cates, G.R., and Mollaghasemi, M., "Project Assessment by Simulation Technique," Engineering Management Journal, Vol. 19 No. 4, December 2007, edited by T. Kotnour, American Society for Engineering Management, pgs. 3-10.

${ }^{10}$ Cates, G.R., Cirillo, W.M., and Stromgren, C., "Low earth orbit rendezvous strategy for lunar missions." In Proceedings of the 2006 Winter Simulation Conference, edited by L. F. Perrone, F. P Wieland, J. Liu, and B. G. Lawson, 1248-1252. Piscataway, New Jersey: Institute of Electrical and Electronics Engineers.

${ }^{11}$ Stromgren, C., Cates, G.R., and Cirillo, W.M., "Launch Order, Launch Separation, and Loiter in the Constellation 11/2Launch Solution," 2009 IEEE Aerospace Conference, Big Sky, MT, 7-14 March 2009.

${ }^{12}$ Linstone, H.A., and Turoff, M. Editors, The Delphi Method: Techniques and Applications. Reading MA: Addison Wesley. 1975

${ }^{13}$ Delbecq, A.L., Van de Ven, A.H., Gustafson, D.H., Group Techniques for Program Planning: A Guide to Nominal Group and Delphi Processes. Middleton, WI: Green Briar Press. 1986

${ }^{14}$ Armstrong, J.E., "Issue Formulation" in Handbook of Systems Engineering and Management, edited by Sage, A.P. and Rouse, W.B., New York: John Wiley. 1999.

${ }^{15}$ Expert Fit User's Guide. Averill M. Law and Associates.
} 


\title{
Statistical and Probabilistic Extensions to Ground Operations' Discrete Event Simulation Modeling
}

\author{
Linda Trocine, Ph.D. - PAl 1 \\ Nicholas H. Cummings - NASA KSC ${ }^{2}$ \\ Ashley M. Bazzana - PAI \\ Nathan Rychlik - PAI \\ Kenneth L. LeCroy - PAI \\ Grant R. Cates - SAIC ${ }^{3,4}$ \\ Mansooreh Mollaghasemi - PAI
}

${ }^{1}$ Productivity Apex, Inc., Orlando, Florida

2NASA's Kennedy Space Center, Florida

${ }^{3}$ Science Applications International Company, McLean, Virginia

${ }^{4}$ Senior AIAA Member 


\section{DES Analysis Methodology}

Discrete Event Simulation is a computer-based modeling technique for complex and dynamic systems where the state of the system changes at discrete points in time and whose inputs may include random variables.

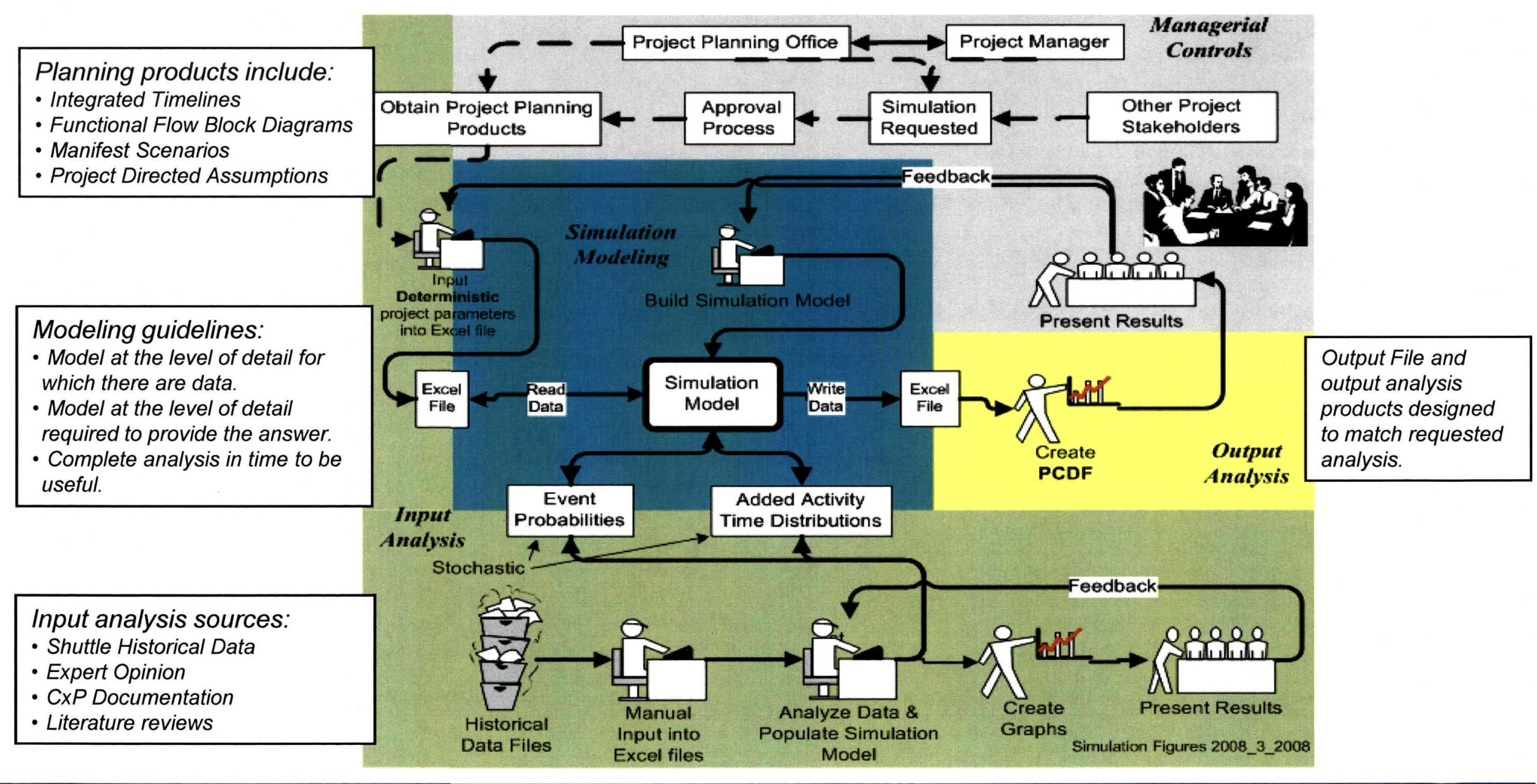




\section{Process Overview}

Input

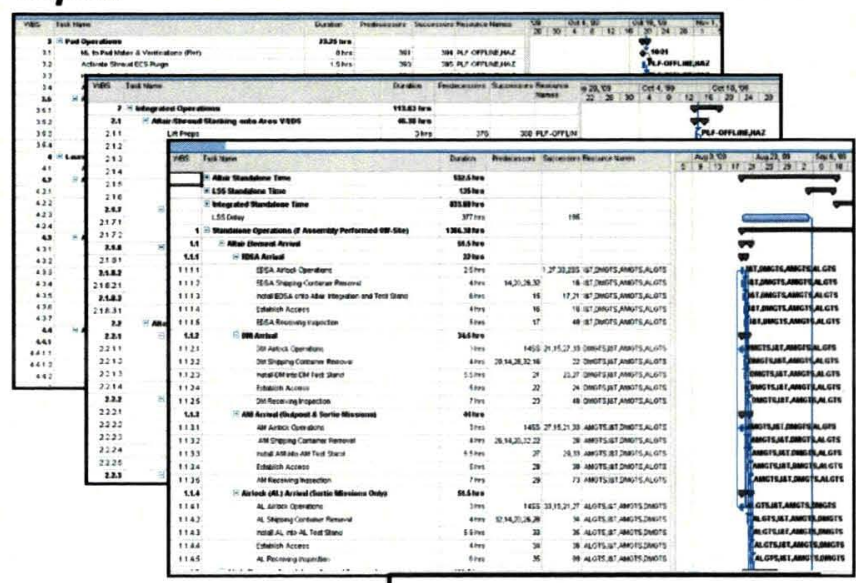

GOPD Timelines

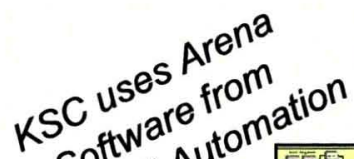

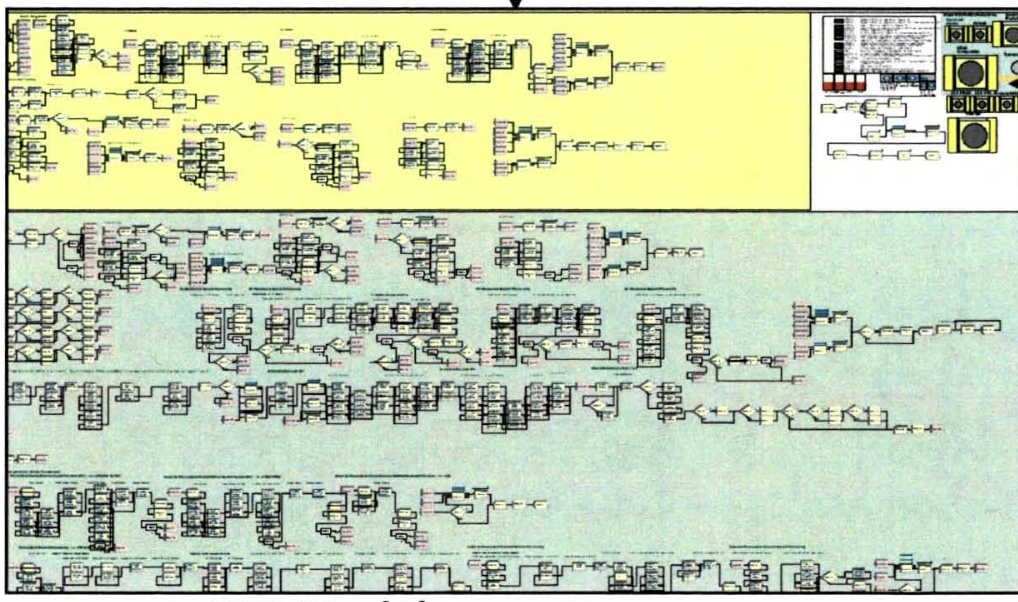

DES Models

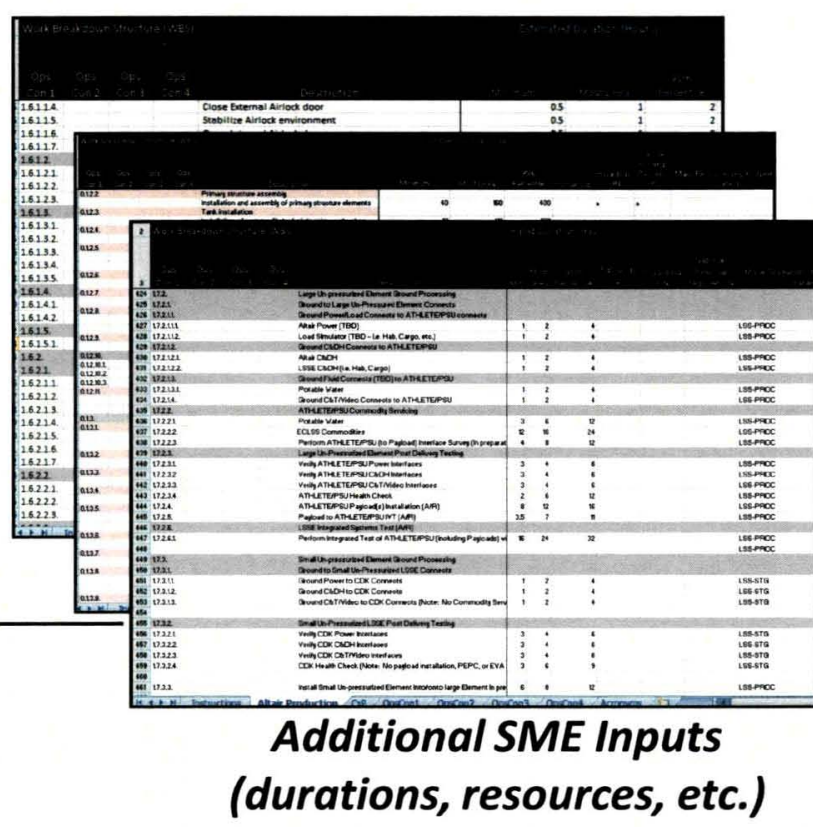

RockNell Aul

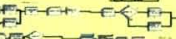

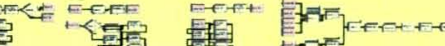
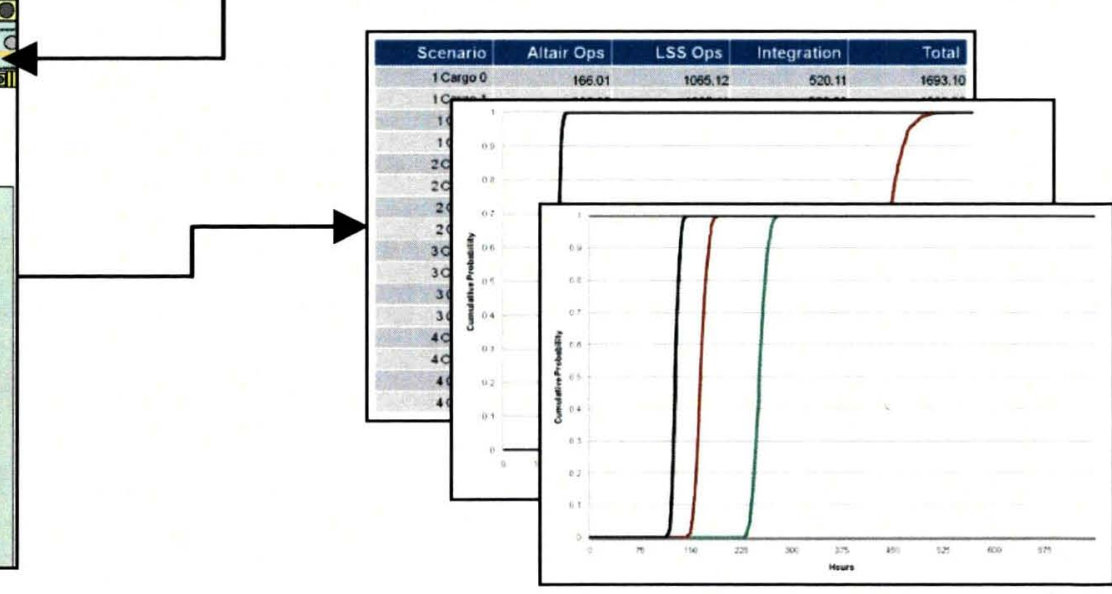

Output Results 


\section{Examples of DES Successes at KSC}

- The Vehicle Assembly Building High Bay Assignments for Ares I and Ares V Vehicle Integration Activities

- Launch Order and Spacing of Ares I and Ares V Combined missions

- Ground Operations Preliminary Design Review (PDR) Requirements Compliance Analyses

- Validation of Single String Processing Architecture to Save Maintenance Costs

- Trade Studies for Optimum Facility Selection for Altair and Lunar Surface Systems Processing

- Validation of Critical Path Processing Flows

- Optimization of Launch Complex Operations 


\section{An Example of DES Used For Critical Path Analysis}

- Critical Path Requirement (879 hours)

- Analysis revealed about $10 \%$ probability that the nominal timeline will require no more than $934.4 \mathrm{hrs}$ and about $90 \%$ probability that it will require no more than $965.72 \mathrm{hrs}$

- Mean - 949.5 hrs

- GOPD timeline single-point estimate duration $-855.18 \mathrm{hrs}$

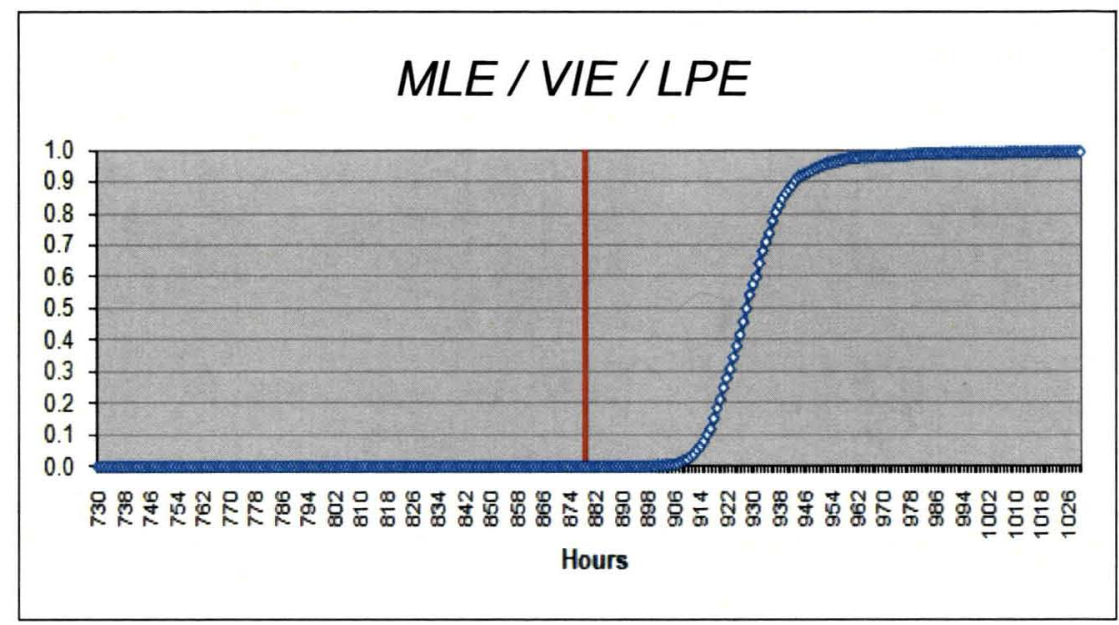

GOTAR DES Analysis Trend

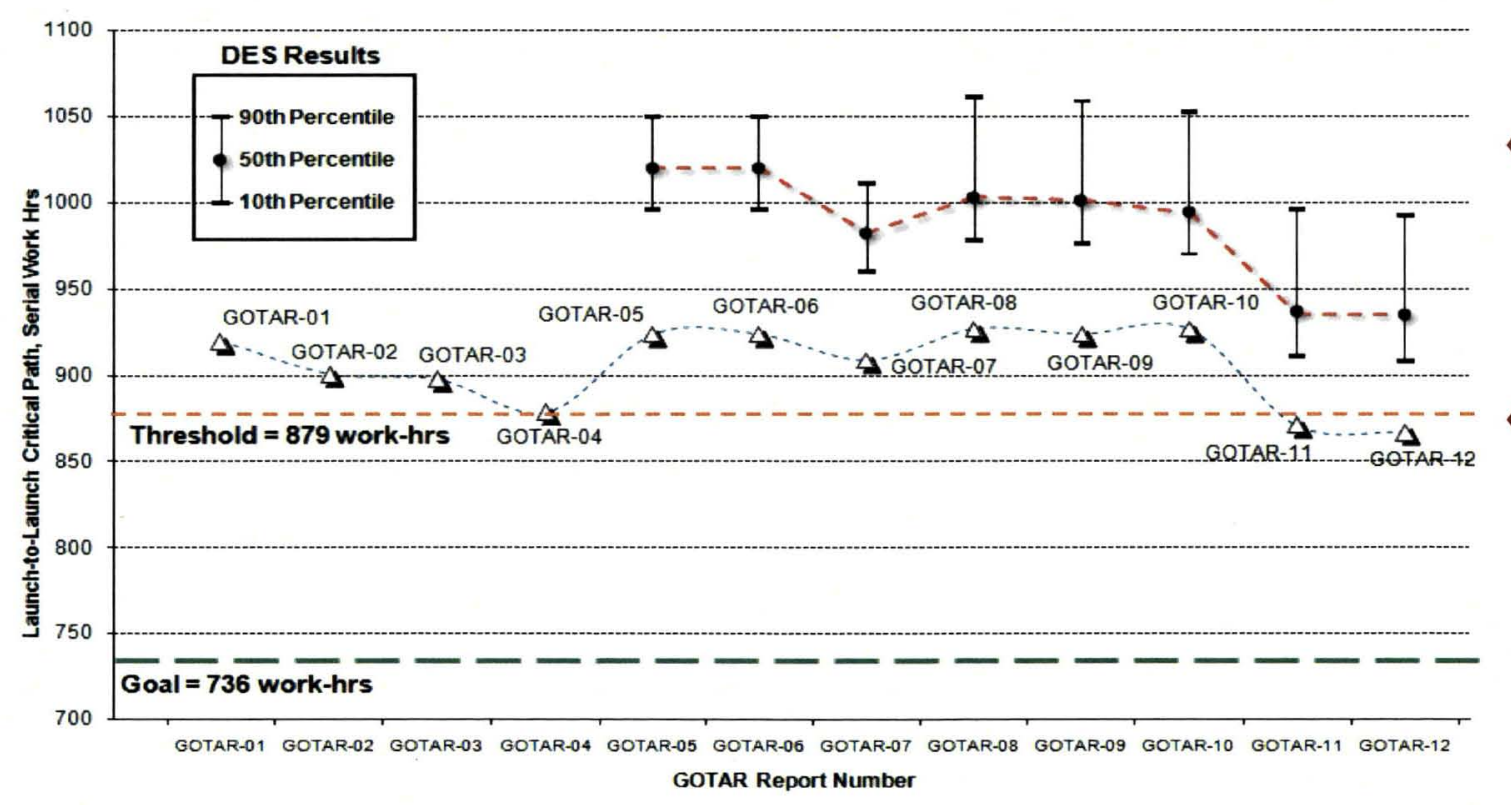

- The vertical bars show the effect of common cause variability in the task time estimates for the process flows, based on expert opinion.

- Opportunities exist to continue to reduce the total critical path

- Incorporation of Interstage FOD net

- LAS to CM offline integration 


\section{Three Extensions to DES Use at KSC}

- Delphi Method

- Created by Rand Corporation and U.S. Air Force in late 1950s.

- Extended here to collect subject matter expert task duration estimates used for fitting theoretical input distributions for DES models. Useful for new spacecraft designs where historical data do not exist.

- Probabilistic Event Variation

- Arena DES models have "decide" modules to choose alternative paths for the processing flow, typically using a fixed probability (e.g. 30\% path $A$ and $70 \%$ path $B$ ). The team extended Arena's capability by varying these probabilities, such as with the Normal Distribution, because the probability is not known with certainty.

- Roll Up Method

- No literature was found for summarizing detailed DES models to be reused in less detailed DES models.

- Some basic experiments were conducted to derive rules of thumb. These rules of thumb were used extensively to summarize and reuse portions of DES models in other models and are described here. 


\section{Delphi Method}

- The Delphi Method is a structured elicitation method for forecasting, estimating, and planning used with a group of subject matter experts in the absence of sufficient data.

- Anonymous opinions

- Convergence to unbiased estimates

- Scientifically valid results

- Excel based worksheets

- Median values for triads
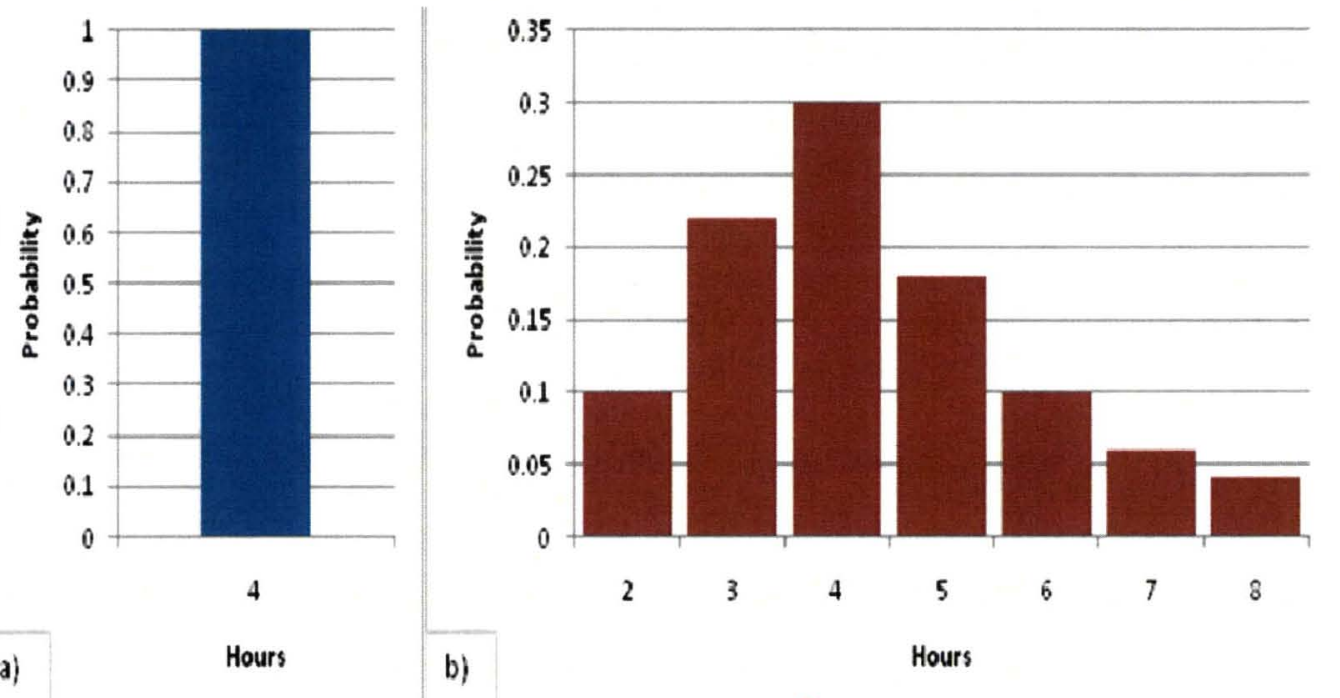

\begin{tabular}{l|c|c|r|} 
& Responded & Total & $\begin{array}{r}\text { Percent } \\
\text { Respond }\end{array}$ \\
\hline First Project & 42 & 67 & $63 \%$ \\
\hline Second Project & 22 & 47 & $47 \%$ \\
\hline Third Project & 26 & 69 & $38 \%$ \\
\hline
\end{tabular}

b)

Task time 


\section{Consumer's Risk Approach to Requirement Acceptance}

A sample is drawn. The proportion of "pass" items to the total number of items is used to infer the proportion of the underlying population. The sample may be drawn from either a good or bad design.

To reduce $\beta$,

\section{- increase $\alpha$,}

- increase sample size, or

- increase hypothesized difference.

$\beta=$ Type II error, Consumer's risk "a bad system is accepted as good"

\begin{tabular}{|l|cc|}
\hline \multicolumn{2}{|c|}{ Underlying Truth } \\
\hline $\begin{array}{l}\text { Sample's } \\
\text { Test Result }\end{array}$ & Good Design & Bad Design \\
Design & $\checkmark$ & $\begin{array}{c}\boldsymbol{\beta} \\
\text { Type II Error } \\
\text { Consumer's Risk }\end{array}$ \\
\hline Bad Design & $\begin{array}{l}\text { a } \\
\text { Type I Error } \\
\text { Producer's } \\
\text { Risk }\end{array}$ & $\checkmark$ \\
\hline
\end{tabular}

The proportion of simulation replications that "pass" was used to infer whether the system meets a requirement or not within the Consumer's risk ceiling.
$H_{0}: p_{1}-p_{0}=$ difference Where $p$ is proportion of failures to opportunities $\alpha=$ Type I error, Producer's risk

"a good system is rejected as bad" 


\section{Probabilistic Event Variation}

- Conditional probabilities of crew rescue abort events, which depend on phase of flight and abort location.

- Estimated by experts, subject to variance

- Allows for consumer's risk approach to requirement verification
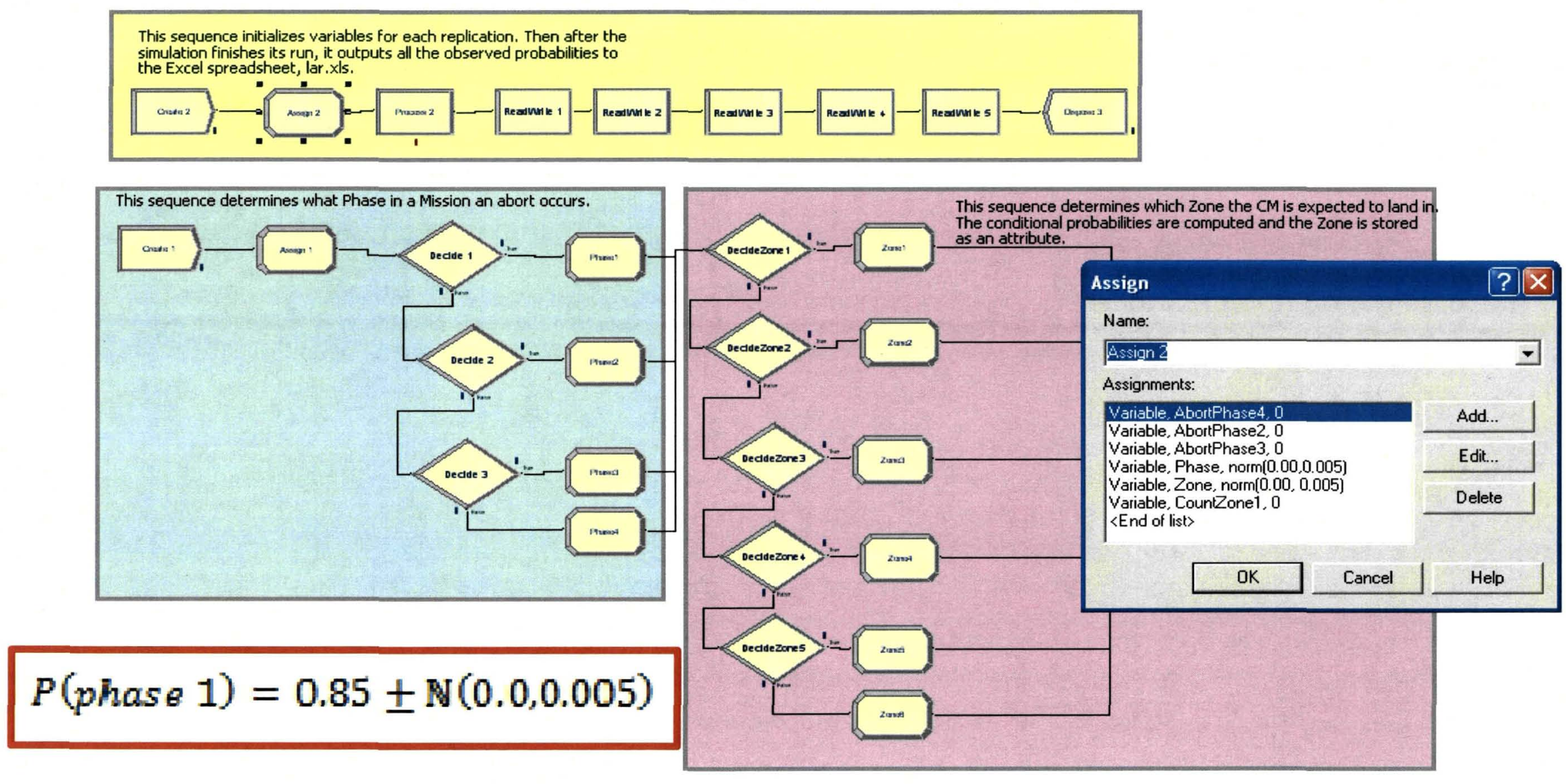


\section{Roll Up Method}

- A method was needed to reuse parts of more detailed DES models into parts of less detailed models. Experiments:

Controlled Variables

Number of Tasks

4

12

30

\section{Independent Variables}

Distribution

Number of

Replications

30

200

1000
Triangular

Weibull

Lognormal

- Rules of thumb: For each sequence of tasks that needed to be rolled up, 200 replications using lognormal as the underlying distribution were used to fit less detailed distributions.

- More research should be done to evaluate when resources and parallel operations dominate the summary results and to investigate the theoretical basis for summarizing detailed DES models. 


\section{Example of Roll Up Method}

Using the GOTAR-07 DES Model, 200 output observations of the total time among the tasks within the Pad Operations processing segment were analyzed using Expert Fit to create rolled-up input distributions for the Surge Capacity model.

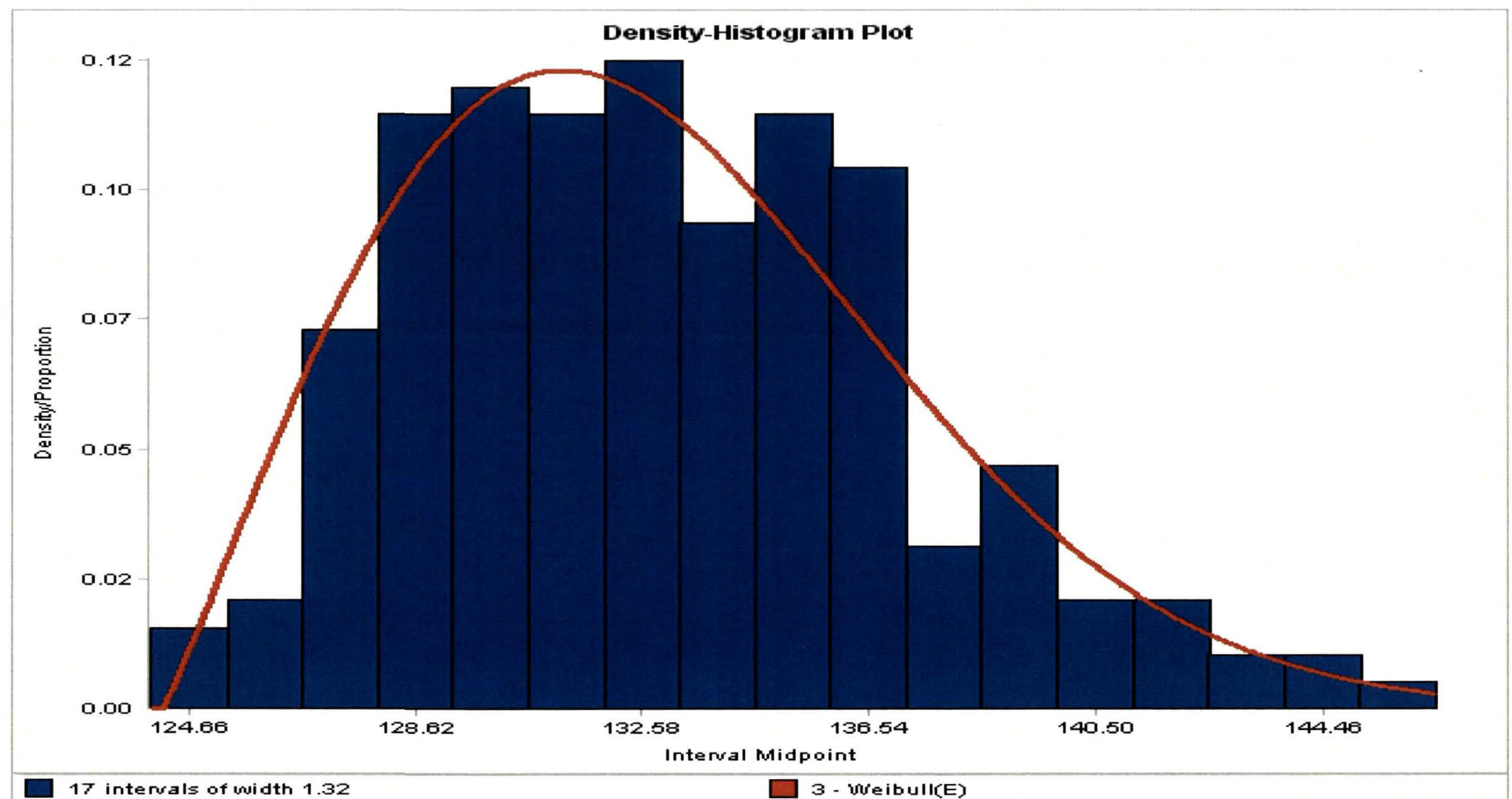




\section{Acknowledgments}

- The authors thank the

- Orion Processing Team for being the pathfinder on the Delphi method,

- Orion Landing and Recovery Team for being the pathfinder on the probabilistic event variability technique, and the

- Level II team for supporting the development of the roll-up method.

- This work was sponsored by the Constellation Program Ground Operations Project at NASA's Kennedy Space Center. 


\section{References}

- Banks, J, Carson, J.S., Nelson, B.L., and Nicol, D.M., Discrete Event Simulation, 3rd Edition, Prentice Hall International Series in Industrial and Systems Engineering, 2001.

- Law, A.M., Simulation Modeling \& Analysis, $4^{\text {th }}$ Edition, McGraw Hill, 2007.

- Archer, M. and J. Leotta, "Simulation Study: KSC Shuttle Processing," briefing charts 1994. See NASA Tech Briefs, "Software for Planning in a Hierarchical Processing Environment," Feb 1998, pg. 76, for a brief description of this work.

- Cates, G.R., Steele, M.J., Mollaghasemi, M., \& Rabadi, G., "Modeling the Space Shuttle," In Proceedings of the 2002 Winter Simulation Conference, edited by E. Yücesan, C.-H. Chen, J. L. Snowdon, and J. M. Charnes, 754-762. Available via www.informscs.org/wsc02papers/097.pdf.

- Kaylani, A., Mollaghasemi, M., Cope, D., Fayez, S., Rabadi, G. and Steele, M.J., "A generic environment for modeling future launch operations-GEM-FLO: a success story in generic modeling," Journal of the Operational Research Society $(2008) 59,1312-1320$.

- Mollaghasemi, M., Steele, M.J., Rabadi, G., and Cates, G.R., "A Generic Environment for Modeling Future Launch Operations (GEM-FLO)," World Automation Congress, June 2002, Orlando, Florida

- Cates, G.R., and Mollaghasemi, M., "Supporting The Vision For Space With Discrete Event Simulation," In Proceedings of the 2005 Winter Simulation Conference, edited by M. E. Kuhl, N. M. Steiger, F. B. Armstrong, and J. A. Joines, 1306-1310. Available via http://www.informs-sim.org/wsc05papers/159.pdf

- Cates, G.R., and Mollaghasemi, M., "A Discrete Event Simulation Model For Assembling The International Space Station," In Proceedings of the 2005 Winter Simulation Conference, edited by M. E. Kuhl, N. M. Steiger, F. B. Armstrong, and J. A. Joines, 1260-1264. Available via http://www.informs-sim.org/wsc05papers/153.pdf

- Cates, G.R., and Mollaghasemi, M., "Project Assessment by Simulation Technique," Engineering Management Journal, Vol. 19 No. 4, December 2007, edited by T. Kotnour, American Society for Engineering Management, pgs. 3-10.

- Cates, G.R., Cirillo, W.M., and Stromgren, C., "Low earth orbit rendezvous strategy for lunar missions." In Proceedings of the 2006 Winter Simulation Conference, edited by L. F. Perrone, F. P Wieland, J. Liu, and B. G. Lawson, 1248-1252. Piscataway, New Jersey: Institute of Electrical and Electronics Engineers.

- Stromgren, C., Cates, G.R., and Cirillo, W.M., "Launch Order, Launch Separation, and Loiter in the Constellation 11/2-Launch Solution," 2009 IEEE Aerospace Conference, Big Sky, MT, 7-14 March 2009.

- Linstone, H.A., and Turoff, M. Editors, The Delphi Method: Techniques and Applications. Reading MA: Addison Wesley. 1975.

- Delbecq, A.L., Van de Ven, A.H., Gustafson, D.H., Group Techniques for Program Planning: A Guide to Nominal Group and Delphi Processes. Middleton, WI: Green Briar Press. 1986.

- Armstrong, J.E., "Issue Formulation" in Handbook of Systems Engineering and Management, edited by Sage, A.P. and Rouse, W.B., New York: John Wiley. 1999.

- Expert Fit User's Guide. Averill M. Law and Associates. 